found three or four opium pipes, which were made use of occasionally in the course of the day's march. Tobacco, however, was principally made use of during the day, the opium being reserved till the evening, when they would generally commence after supper, and smoke until they could no longer put the pipe into their mouths.

As can readily be imagined, the habitual use of opium, at least as practised by the Chinese, cannot fail to produce the most injurious effects upon the constitution, still more so probably than that of ardent spirits. The peculiar languid and vacant expression, the sallow and shrivelled countenance, the dim and sunken eye, and the general emaciated and withered appearance of the hody, easily distinguish the confirmed opiumsmoker. The mind, likewise, soon participates in the general wreck of the body; and the unhappy individual, losing all relish for society, remains in a state of sottish indifference to everything around him but the deadly drug, now his only solace, which sooner or later hurries its victim to an untimely grave.

The most inveterate opium-smoker that came under our observation during a journey of two months through the interior of the country, was the head policeman under whose charge we crossed from the island of Hainan to the mainland of China. This individual, who was evidently an old stager, went through the operation with great neatness and dexterity, commencing soon after he came on board the junk which conveyed us across the strait (about five in the afternoon); he continued without intermission till midnight, when tired with observing him, I fell asleep.

The refuse of the pipe is likewise much prized, especially where a superior specimen of the drug has been made use of, and is generally the perquisite of one of the servants, who forms it into pills, by mixing it with a little oil, to which he treats himself while his master is in a state of oblivion.

The poppy is said to be extensively cultivated in some of the southern provinces of China, but during a journey of nearly six hundred miles, embracing the whole extent of Hainan, and part of the provinces of Quang-see and Quang-tung, we never met with a single specimen.

\section{UNDILUTED CREOSOTE IN BURNS.}

\section{To the Editor of The LanceT.}

Sir,-It has been my intention for some time to send you a short communication on the use of undiluted creusote in burns, but $I$ have delayed doing so in the expectation that I might be able to try the remedy in a greater number and variety of cases, so as to obtain an estimate of its real value. In the 22nd Number of The La Nont, how there is a communication from Dr. Mhteht of Dublin, on the subject, in which the th thor requests information from other went bers of the profession who may have nsed li and in consequence of this I shall state shorth the result of my experience.

About two years ago I accidentally dropped some burning sealing-wax on m hand; I removed it as quickly as possible, and applied to the surface a drop of creo sote from a bottle which happened to beside me ; it afforded immediate relief, and in less than five minutes the pain was gone No sensible vesication took place, but in few days the cuticle peeled off, and left dry, reddish surface beneath. A short time after this one of my servants burned the palm of her hand by laying hold of a hot iron; in a few minutes creosote removed the pain, and I heard nothing more of it. I have used it in ten or a dozen similar cases, and I have always found it remove the pain in a very short time. The effects $I$ had observed induced me to bring the subject before the Medical Institution of Liverpool (as I find by the minutes), on the Ist of April, 1841, in the hope that such members as had opportunity might give the remedy a trial. I have had no experience of its use in severe inju: ries, and on this point I can bear no testimony, but in the common domestic burn or scald it has appeared to me so useful that 1 have rccommended its being kept in families for the purpose of immediate application. I am, Sir, your obedient servant,

John Suther Land, M.D.;

Honorary Physician to the North Dispensary.

Tiverpool, Feb. 28, 1842.

P.S.- The best way to apply the ereosote I have found to be to brush the surface over with a hair pencil dipped in the liquid, and to renew the application as often as may be necessary; part of the creosote is absorbed, and the cuticle should be kept moistened till the pain is relieved.

\section{NEW OBSTETRICAL INSTRUMENT, THE KEPALEPSALIS. \\ By Willia Campbell, M.D.,}

Fellow of the Royal College of Surgeons, Edinburgh, \&c. \&c. \&c.

To the Editor of The Lancet.

SIR, - When I inform you that the instrument which bears the above desiguation is considered by the profession here the most important addition that has for many years past been made to our obstetric inventions, 1 feel confident that you will give the following description and brief observations regarding it a place in your valuable Publication.

In the operative department of midwifery, a mechanical power calculated to reduce the 
Whith as little suffering as possible to parent and ease to the practitioner, to Toessary extent in cases of the greatest I of confinement of the pelvis, which is with safety to the maternal strucadmit of embryotomy, has hitherto desideratum which every practiwho has ever felt or reflected on the wities attendant on cases of extreme desity, must have been most anxious to 61y. The plan hitherto adopted, when it tine necessary to reduce the skull, has by means of an instrument upon the hioiple of forceps with lengthened handles, temore not by cutting, but by tearing, fiting, or wrenching successive portions the bones. This procedure, whether in tres of considerable deformity or otherHa, is attended with so much difficulty, and tuires so much force in its performance as ioccasion great suffering to the parent Whessive labour to the practitioner; dimoreover, until decomposition to a ceriip extent has taken place in the foetal ruetures, the bones forming the face and hase of the cranium cannot be acted on by

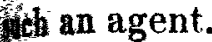

The late Professor Davis, of the London Diversity, who was an enthusiast in this department of midwifery, and was, moreitet, possessed of considerable mechanical Hent, laid claim to the invention of an indrument which, to say the least, is ingeniins; and were we to take for granted all fat he has written regarding it, the desideatum in question might have been condidered as completely supplied, since we are formed in the writings of Dr. Davis, that io great was the utility of the contrivance in inestion, that it could be efficiently used with pelvis of only one inch of space betwixt the promontory of the sacrum and the symphysis the pubes; thus "reducing to zero the essity for performing the Crsarian secton," and so extraordinary its power, that it rould cut through " beef-ribs." A superfial but an impartial examination of $\mathrm{Dr}$. Davis's instrument (osteotomist) will at ance, however, convince any one that it is ingenious, though not in every degree a uccessful attempt, to supply what has been wanting.

I am happy to say that what has been so much required has, in a great measure, if ot completely, been supplied by Mr. Simpson, surgical instrument-maker, of this city. The merit of the invention, and which by the profession here is considered great indeed Sentirely due to Mr. Simpson. I claim no share of it, further than having pointed out to the maker how inadequate Dr. Davis's instrument was to accomplish the important object in view; what was particularly required in cases of extreme deformity, and from time to time offering such suggestions as might be calculated to improve the power and utility of the instrument. The kepalep- salis is so constructed that it may be applied with perfect safety to the maternal structures in any pelvis with a space of only one inch and an eighth between the promontory of the sacrum and the symphysis pubis: it cuts out the piece of bone within its grasp with such facility, as to require but a very moderate degree of power from the operator; it is capable of removing large portions of the skull in each successive application, whereby our object is attained with comparative expedition; and, finally, while one or more portions of bone, after being separated, are still lodged in the instrument, other pieces may be cut away, and the whole simultaneously extracted by the instrument itself; thus superseding in this part of the process the use of the fingers. The only difficulty that can be experienced in the application of this contrivance is one inseparable from every case in which such aid can be required, whether the confinement of the pelvis be extreme or not; viz., placing, during its successive applications, the presenting part of the cranium within its grasp. If a plate of mahogany, or of any other kind of hard wood, the thickness of one of the cranial bones of the foetus, be covered with thick chamois leather, and placed within the grasp of the kepalepsalis, the great ease with which the included portion is cut through will afford a good idea of the powers of this agent.

The following is a description of the kepalepsalis in Mr. Simpson's own words:-The length of the instrument is thirteen inches and a half; that of the cutting part two inches and a half; and of the handles eleven inches. It is formed on the principle of scissors, but differs from them in so far that, instead of making a division, it affects the separation of the entire portion placed within its grasp. This is effected by continuing the outer blade round the extremity of the inner one, and returning it along the opposite side, as far as the joint or screw, where it forms one solid piece with the handle. When open, the blade resembles a box, two inches in length and half an inch in width, into which the inner blade is accurately fitted, and the cutting action is performed by the edges or corners of this blade passing those of the outer one into the box, as the handles approach each other. It will with equal ease remove a piece about the size and shape of the index-finger, and half an inch wide; or the most narrow portion it may be necessary to detach, as from the peculiar construction of the blades they cannot be thrown from their acting position. 